\title{
The Aesthetics of Still Life Photography at Home During Covid-19 Pandemic: Designing Mobile Photographic Works
}

\author{
Ardiles Akyuwen ${ }^{1, *}$ Cininta Analen ${ }^{2}$
}

\author{
${ }^{1}$ Universitas Multimedia Nusantara \\ ${ }^{2}$ Lembaga Studi Indonesia Malaysia \\ *Corresponding author. Email: ardiles.akyuwen@umn.ac.id
}

\begin{abstract}
Still life photography has long been used as a medium of expression and for conveying information and ideas, as well as representing the identity of a person or a group. Still life photos can touch the heart of the viewers and make them feel connected with the stories behind the photos. Thanks to the rise of mobile photography, creating still life photos is now easier and faster, with just a few clicks on a camera application available in every smartphone. This type of photography is also facilitated with various digital darkroom applications and social media as a publishing platform. Still life photographs using mobile phones can be an alternative medium to tell the story about Jakarta urban families life during the COVID-19 PSBB. Everyday objects closely related to the photographer, such as dog leashes, an air conditioner, a glass, a wiper stick, and a burger can aesthetically tell stories about a home. In order to make the stories relatable and enjoyable for the viewers, proper research methodology and design method are required. The author used qualitative research methodology to collect information and data about the life of urban families in Jakarta under the implementation of PSBB. As the starting point for the design method, data and information gathering is followed by brainstorming, conceptualization, experimentation and development, and execution.
\end{abstract}

Keywords: Still Life Photography, Mobile Photography, PSBB, COVID-19 Pandemic.

\section{INTRODUCTION}

Photography, especially mobile photography, continues to grow impetuously thanks to cyberculture, which manifests in various human-to-computer relations. Mobile cameras, applications, and social media are now an inseparable part of most everyday human activities and social interactions.

Cyberculture can be defined as the entire culture that has emerged through the use of computer networks for communication, entertainment and business. It is also the study of various social phenomena associated with the Internet and other new forms of network communication, such as online communities, online multiplayer gaming, social gaming, social media and texting, and includes issues related to identity, privacy, and network formation.

In cyberculture, we can find visual culture which refers to the tangible and visible expressions in a community, nation, or civilization. These expressions describe the collective identity and characteristics of the people. The form of visual culture can be found in performing arts, fine arts, and documenting arts.

One important and oldest part of photography is still life photography that is basically a collection of inanimate objects arranged as a composition so that they bring aesthetic pleasure. By arranging settings, lighting and composition, still life photographers can breathe life into the objects.

Still life photography has its own aesthetic vocabulary, which can be explored from basic idea generation to implementation with photographic equipment and techniques. In still life photo experiment, it is not uncommon for each object to be photographed several times from different angles, using various focal lengths and lighting combinations. The goal is to obtain a variety of photos with different aesthetics, thus providing the best alternative photo options. 
Still life photos have become the prima donna for many artists, not only photographers, but also visual storytellers, and graphic designers to express themselves. This genre of photography can also be a medium for storytelling, and reflects the identity of a person, group or civilization.

And now, the practice of still life photography is increasingly common thanks to the explosion of mobile photography. Now anyone can do the entire photography process, from taking to presenting photos, easily, quickly and correctly, with just one click on the camera application on a mobile device.

But more than taking pictures, mobile photography is taking place in the world of visual communication as a medium to tell the stories of daily life of its users through social networks. This trend is facilitated by various digital darkroom applications, as well as advanced photography features on social media, including filters and effects.

The COVID-19 pandemic has forced people to stay at home and socially distancing in order to flatten the pandemic curve. This has resulted in geographically limited space for photographer. But, on the other hand, these limitations encourage creativity in photographing methods and techniques.

In this project, the author opted to create still life photographs by means of mobile phone as a medium to tell the story of urban Jakarta family life under the large-scale social restriction (PSBB) that orders people to stay home in response to the COVID-19 Pandemic. Everyday objects closely related to the author's daily life are portrayed using a mobile phone that makes the process easier and faster. Digital darkroom application helps in editing the photos to breathe life into the objects and better portray the comfort of staying at home. Mobile photography also makes it easy to upload photos to social media.

The purpose of this project is to tell the life of an urban Jakarta family during the COVID-19 pandemic, through still life photos and mobile photography as alternative media in visual storytelling. As an expression of creativity, the author/photographer used shooting procedures in studio photography and documentary photography, with shallow and deep DOF (deep of field) techniques.

\section{LITERATURE REVIEWS}

\subsection{Aesthetics of Still Life Photography}

According to Mikke Susanto, aesthetics is: "1. About beauty and appreciation of beauty; 2 . Examining beauty;
3. Things related to beauty and taste..." [1]. He explaines that the word aesthetic is derived from Greek word "aishtetikos" which means things that are perceived by human senses and lead to feelings, as opposed to things known by the mind.

Dharsono notes Herbert Read's definition of aesthetics: "Generally, aesthetics is the philosophical study of beauty; from how beauty is created to how to feel and value its presence. Herbet Read, in his book "The Meaning of Art", defines aesthetic or beauty as a unity of various forms that has meaning and can be perceived by the human senses..." [2]. This also applies to aesthetics in photography as a medium for conveying messages or information, and storytelling in visual communication design. Aesthetics in photography begins with extracting ideas, then processing them into the concept of a photowork. Designing the concept starts from technical aspects by exploring aesthetic values with photo shooting techniques. then determining the concept from a technical aspect by exploring aesthetic values through photo shooting techniques.

[3] define still life photography as: "Creating an image of an inanimate object so that it appears alive and speaks, such as food that looks warm, cold or soft. The word 'still' refers to immovable or inanimate objects, while 'life' provides a context of "appearing alive" in that object..."[4]. The aesthetics of still life photography is basically photographing a collection of inanimate objects arranged as a composition so that they look alive. The arrangement consists of layout, lighting (direction of light), shooting angle, based on the photographer's ideas and concepts.

\subsection{Mobile Photography}

Photography has been changing and evolving for centuries and found a new face in the era of smartphones. Now anyone can do the entire photography process, from taking to presenting photos, easily, quickly and correctly, with just one click on a camera application on smartphones. This new type of photography known as mobile photography is getting even easier thanks to the many digital darkroom applications available on smartphones, as well as advanced photography features on social media, including filters and effects.

Mobile photography is more than just capturing images, this type of photography has now leveled up and transformed into a part of visual communication. Through social media, users can convey any information and tell about their daily activities through photos. Also, the mobile photography trend has been growing vastly in the creative industries, with 
practitioners selling their photos through various digital platforms, becoming brand endorsers, or designing supporting applications.

\section{DESIGN METHOD}

Soeprapto Soedjono founds that, "Photography as an entity in fine arts cannot be separated from the aesthetic values and principles of fine arts. However, each genre of fine arts also has its own aesthetic values and vocabulary, as does photography with its various subgenres..." [4].

The aesthetics of photographic works consist of two levels, aesthetics at the ideational level and aesthetics at the technical level. At the ideational level, aesthetic values are related to conceptualizing photography as a medium for conveying information, while the technical level includes extracting aesthetic values through photo shooting techniques.

After processing the idea and concept, the next stage is creation. In its creation, photography has two functions; as a medium for documenting reality, and as a medium for artistic expression. In its nature as a medium for documenting reality, photography is closely related to everyday life and the socio-cultural development of society. It shows urban or rural life, natural life, modernity, people's expressions, landscape, culture, fashion, joy, beauty, sorrow, destruction, war and social change.

Kristin Cullen states that, "Design is a process of discovery. It is a journey that reveals communication through distinct stages, which include research and information-gathering, brainstorming, conceptualization, experimentation and development, and execution..." [4].

To make sure the creation stage is in line with the ideas and concept so as to produce good photos, design method of photographic works should include research and information-gathering, brainstorming, conceptualization, experimentation and development, and execution. Design method acts as a guidance from initiation to completion.

1. Research and Information Gathering.

The author collects information through literature study and observation, as well as interviews to collect qualitative data about the life of urban Jakarta families under social restrictions in response to the COVID-19 pandemy.

2. Brainstorming.
The information and data were then organized through brainstorming in order to map the phenomena in urban societies under PSBB COVID-19. Brainstorming is divided into four steps; freewriting, mindmapping, outlining the ideas, and selecting visual references. At this stage, the author decided to create still life photographs using mobile photography as an alternative medium to tell the story about Jakarta urban families life during the COVID19 PSBB.

\section{Conceptualization.}

After the brainstorming stage, the author made a concept consisting of several elements; objects positioning and layout, lighting, point of view (angle), shooting view, composition/control frame, and photography techniques. All of these element are summarized in a shooting diagram.

4. Experimentation and Development.

In implementing the concept into photo works, the shooting for every photo is carried out several times to get maximum results.

5. Execution.

At this stage, the author finalizes the photo shoot, followed by editing, sequencing, adjusting the photos using digital darkroom applications, before presenting them on social media.

\section{DESIGN PROCESS}

Design process of photographic works starts from research and information-gathering and ends with execution, as described in figure 1.

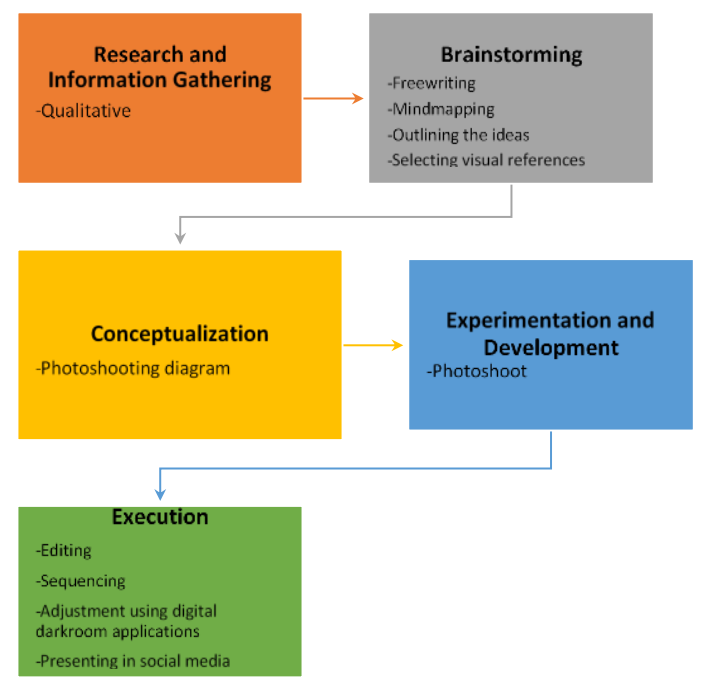




\section{Figure 1 Design Process.}

Before conceptualizing, the author conducted a research through literature studies, observations, and interviews to collect qualitative data about the life of urban families living in Jakarta under the COVID-19 PSBB.

The collected information and data were then organized through brainstorming in order to map the phenomena in urban societies under PSBB COVID-19. At this stage, the author decided to create still life photographs using mobile photography as an alternative medium to tell the story about Jakarta urban families life during the COVID-19 PSBB.

\subsection{Still Life Photo Shooting}

The flow and process of still life photo shooting begins with conceptualization, followed by experimentation and development, and ends with execution.

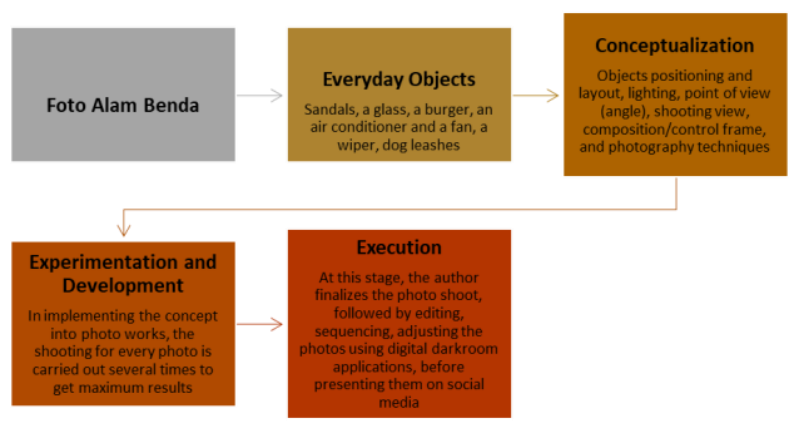

\section{Figure 2 Flowchart of still life photo shooting} process.

\subsection{Still Life Photos as Media for Storytelling}

Still life photography itself is capturing inanimate objects arranged as a composition so that they appear aesthetically alive. The arrangement consists of objects positioning and layout, lighting, point of view (angle), shooting view, composition/control frame, and photography techniques. When arranging the objects, the photographer can explore the aesthetic values.

Still life photography has always been an important part of every stage of photography evolution because of its use as a medium of expression and for conveying information and ideas, as well as representing the identity of a person or a group. It can touch the heart of the viewers and engage them to connect with the stories behind the photos. The objects presented in the photos are usually objects of interest or with closeness factor to the photographer. In this photo project, the author chose some objects in his everyday life to portray stories about his home and family, such as an air conditioner, a fan, a burger, and dog leash.

In all the photos, the author did not do a lot of object arrangements to create certain scenes, and there is no excessive process of creativity through photographic techniques. The author focused on objects just here they are and use minimal lighting inside the house to portray his life under COVID-19 PSBB. Through the photo works displaying everyday objects, the author hopes that viewers can feel connected to the story being told about an urban family in Jakarta under COVID-19 PSBB.

Making storytelling still life photographs involves three technical stages: conceptualization, experimentation and development, and execution that are important in turning ideas into photographs that tell stories. Through the implementation of all three stages the author created six photographs.
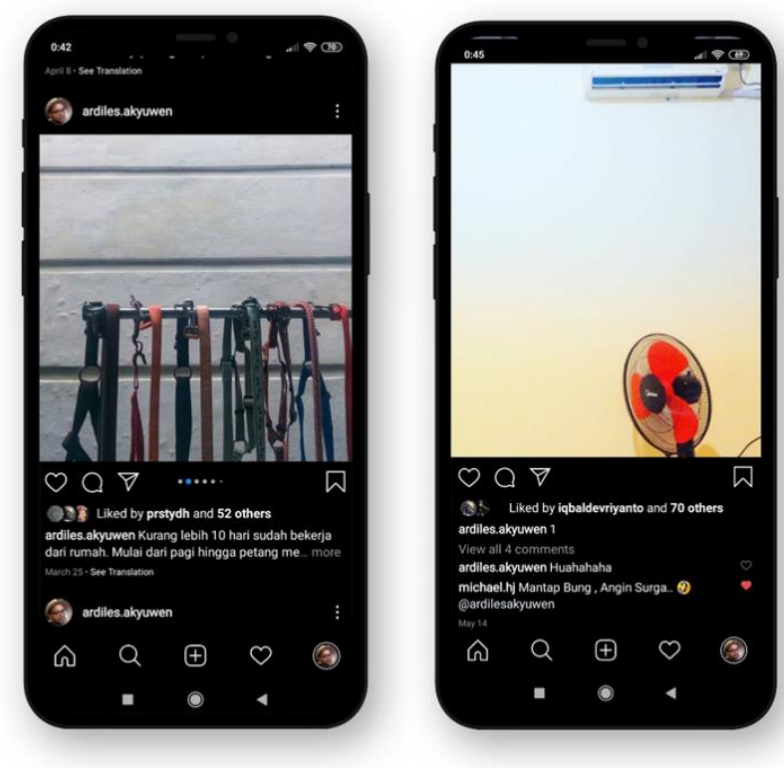

Figure 3 (left) Fading Colours and Figure 4 (right) Heavenly Air.

Fading Colours. Gading Serpong, 2020. Ardiles Akyuwen.

The object of the photo is a row of faded dog leashes hung on a drying rack, captured using a balanced composition, the way in which the frame is divided into two parts, white on top and a row of chains below. The shot was done in an eye level angle so the leashes look as they are, without distortion effects. A deep DOF (deep of field) technique gives sharpness or focus on the entire surface of the object, while the light from above results in high contrast on the object. With these photography techniques, it can be seen that the focal of view of the photograph, titled "Fading Colours", is the 
dog leashes. Through focal of view, the author tries to tell story behind the object. The leashes are used to walk our eight dogs every other day. The dog walking routine is one of the author's family favourite activities during PSBB because it also serves as an exercise for us.

Heavenly Air. Gading Serpong, 2020. Ardiles Akyuwen.

The objects of the photo are an air conditioner (AC) that is running to cool the room, and a fan below it, shot using a balanced composition by dividing the frame into two parts, white wall on the left, and the objects are parallel on the right. Eye level shot keeps the AC and the fan in their original shape. Deep DOF technique adds sharpness or focus on the entire surface of the objects, while light from the upper front adds flat effect to the objects. This technique shows that the AC and the fan are the point of interest of this photo work, titled "Heavenly Air". Through its point of interest the photo tells a story about the AC and the fan that are turned on alternately to cool the bedroom, which also serves as a working space and is the most occupied room during PSBB.


Figure 5 (left) Breakfast Leftover and Figure 6 (right) New Normal.

Breakfast Leftover. Gading Serpong, 2020. Ardiles Akyuwen.

The object of the photo is an almost empty glass of chocolate drink that was left on the dining table after breakfast. Rule of third composition makes the glass stand out from the other objects. Bird eye view shot results in distortion and the area behind the glass becomes vacant. Shallow DOF technique gives sharpness or focus only on the glass, while light source from above creates a contrasting effect to the mouth of the glass. Through these photography techniques, we can see that the glass is the point of interest of the photo, which the author named "Breakfast Leftover". Using the point of interest in this photo, the author tells that meal times, especially breakfast, are bonding moments for the author's family, which creates positive energy during difficult times in the midst of COVID-19 pandemic.

New Normal. Gading Serpong, 2020. Ardiles Akyuwen.

Photographed using the rule of third composition, the red yoga mat stands out against contrasting white background. The eye level angle shot keeps the mattress in its original shape, while deep DOF technique gives sharpness or focus on the whole object. Hard light from the right provides high contrast. With these photography techniques, it is clear that the yoga mat is the point of interest of this photo. The author named the photo "New Normal" because it was taken at the time the government and public began to buzz the new normal phase. During PSBB period, the mat is used for exercising in the morning, and at night as a dog bed.
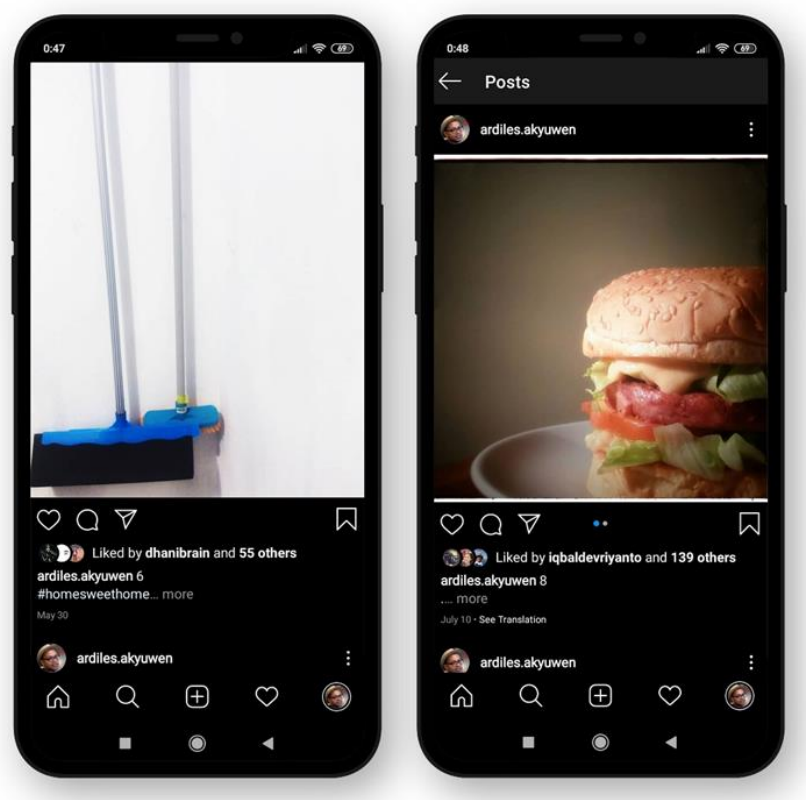

Figure 7 Feeling Blue (left) and Figure 8 Vegan Burger.

Feeling Blue. Gading Serpong, 2020. Ardiles Akyuwen.

This photo uses rule of third composition that accentuates the contrast of the objects, blue wiper and broom, on the blank white background. Eye level shot makes the objects appear in their original form, while deep DOF techniques provide sharpness or focus on the whole object. Harsh light from the left side creates high contrast. Through the point of interest, the author tries to tell that the broom and wiper are routinely used to clean 
the porch and the back of house. The family does the cleaning more frequently to kill both germs and time at home during PSBB.

Vegan Burger. Gading Serpong, 2020. Ardiles Akyuwen.

The author uses the rule of third composition to create a contrasting effect between the burger, as the object, and the dark background. Eye level angle shows the details on the burger, while shallow DOF technique adds sharpness or focus on the details. The light from the left side accentuates the shape of the burger. These techniques highlight the burger as the point of interest of view in the photo. Vegan burger is one of the family's favourite foods. The family has been doing more homecooking since the call to stay home in response to COVID-19 pandemic.

\section{CONCLUSION}

Still life photography by means of mobile photography is an alternative to tell stories about the life of urban families under large scale social restrictions during COVID-19 Pandemic. It can aesthetically depict life at home with its various activities. Everyday objects closely related to the photographer can be captured easily and in no time using a smartphone. Digital darkroom applications help in editing the photos as desired. And through social media, mobile photography makes it easy to publish photo works.

The ease of publishing photos through social media shows that it can serve as a medium for presenting photo works. Therefore, in the next research, the writer will discuss how social media can be used as a digital display.

In addition, the design of this photographic work aims to enrich the knowledge of taking photographs at home to portray current issues. The author hopes that viewers can learn how to create attractive still life photographs with everyday objects in a house, and then connect them with current issues. The output of this design offers a contribution to art projects, commercial photography projects related to home and family.

\section{REFERENCES}

[1] Susanto, Mikke. 2012. Diksi Rupa Kumpulan Istilah dan Gerakan Seni Rupa. Yogyakarta: Dicti Art Lab dan Djagad Art House, p.124.

[2] Dharsono. (2004). Pengantar Estetika. Bandung: Rekayasa Sains, p.10.

[3] Paulus Edison., Indah Lestari Laely. (2012). Buku Saku Fotografi Still Life. Jakarta: Gramedia Pustaka Utama, p.11.
[4] Soedjono, Soeprapto. (2007). Pot Pourri Fotografi. Jakarta: Penerbit Universitas Trisakti, p.7.

[5] Cullen, K. (2007). Layout Workbook: A RealWorld Guide to Building Pages in Graphic Design. Massachusets: Rockport Publisher, p.25. 